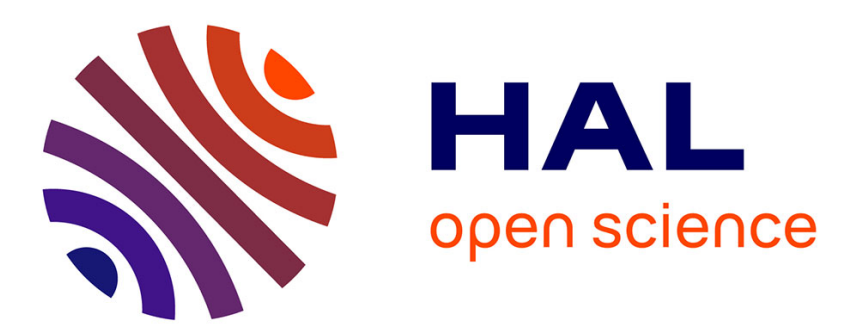

\title{
Total serum cholesterol levels and suicide attempts in child and adolescent psychiatric inpatients
}

Teresa Plana, R. Gracia, I. Méndez, L. Pintor, L. Lazaro, J. Castro-Fornieles

\section{To cite this version:}

Teresa Plana, R. Gracia, I. Méndez, L. Pintor, L. Lazaro, et al.. Total serum cholesterol levels and suicide attempts in child and adolescent psychiatric inpatients. European Child and Adolescent Psychiatry, 2010, 19 (7), pp.615-619. 10.1007/s00787-009-0084-x . hal-00551209

\section{HAL Id: hal-00551209 \\ https://hal.science/hal-00551209}

Submitted on 3 Jan 2011

HAL is a multi-disciplinary open access archive for the deposit and dissemination of scientific research documents, whether they are published or not. The documents may come from teaching and research institutions in France or abroad, or from public or private research centers.
L'archive ouverte pluridisciplinaire HAL, est destinée au dépôt et à la diffusion de documents scientifiques de niveau recherche, publiés ou non, émanant des établissements d'enseignement et de recherche français ou étrangers, des laboratoires publics ou privés. 


\title{
Total serum cholesterol levels and suicide attempts in child and adolescent psychiatric inpatients
}

\author{
Teresa Plana $\cdot$ R. Gracia $\cdot$ I. Méndez $\cdot$ L. Pintor $\cdot$ \\ L. Lazaro $\cdot$ J. Castro-Fornieles
}

Received: 4 February 2009/Accepted: 4 December 2009/Published online: 3 January 2010

(C) Springer-Verlag 2010

\begin{abstract}
Associations between cholesterol and suicidal behavior in adolescent patients have not been explored in depth. In this study, 66 patients consecutively admitted to a psychiatric inpatient unit following attempted suicide were compared with a control group of 54 patients with no history of suicide attempts. The age range of the sample was from 8 to 18 years old. Cholesterol levels were significantly lower in attempted suicide patients than in controls $(p<0.02)$, supporting the hypothesis that lower cholesterol levels might be associated with suicidal
\end{abstract}

T. Plana $(\bowtie) \cdot$ L. Lazaro $\cdot$ J. Castro-Fornieles

Child and Adolescent Psychiatry and Psychology Department, Neurosciences Institute, Hospital Clinic Barcelona,

Centro Investigación Biomédica en Red de Salud Mental (CIBER-SAM), C/Villarroel 170, 08036 Barcelona, Spain e-mail: mtplana@clinic.ub.es

R. Gracia

Child and Adolescent Psychiatry Department,

Hospital Parc Taulí, Sabadell, Spain

I. Méndez

Alicia Koplowitz Foundation Fellowship, Department of Child Psychiatry, University of Pittsburgh School of Medicine, Pittsburgh, PA, USA

L. Pintor

Psychiatry Department, Neurosciences Institute,

Hospital Clínic Barcelona, Barcelona, Spain

L. Lazaro · J. Castro-Fornieles

Institut d'Investigacions Biomèdiques August Pi Sunyer (IDIBAPS), Barcelona, Spain

L. Lazaro · J. Castro-Fornieles

Health Sciences Division, Psychiatry and Clinical Psychobiology

Department, University of Barcelona, Barcelona, Spain behavior in patients with similar acute phase of their disorder.

Keywords Suicide Cholesterol $\cdot$ Adolescents · Child · Inpatients
Abbreviations
CSF Cerebrospinal fluid
5-HIAA 5-Hydroxyindolacetic acid
HVA Homovanillic acid

\section{Introduction}

Suicide attempts occur in various psychiatric disorders, almost half of them $(60 \%)$ in the context of depression [6]. For decades, psychiatrists have sought biological parameters to help them to determine and predict suicidal risk among their patients. Studies of cerebrospinal fluid (CSF) of depressed suicide attempters has identified lower 5-hydroxyindolacetic acid (5-HIAA) and homovanillic acid (HVA) levels in CSF and reduced HVA/5-HIAA ratio as useful biomarkers [7, 13, 16, 17, 28, 31]. Altered function of serotonin transporters and the 5HT2 serotonin receptor also suggest a higher risk of suicidality [24, 29]. Although several studies have assessed the association between lower levels of cholesterol and suicide, the link between peripheral cholesterol and suicidal behavior remains unclear. One of the functions of serotonin in the central nervous system is to avoid harmful behavioral impulses. Engelberg's [10] theory related alterations in membrane microviscosity of cells with dysfunctions in serotonin neurotransmission, and Vevera et al. [34] 
reported that lower cholesterol levels induced viscosity alterations in the cell membrane, with secondary serotoninergic receptor alterations. Lower gray-matter cholesterol in some cortical brain areas has also been related with violent suicide completers [22].

This research generated a conceptual framework for molecular genetic studies on the association between genes encoding for lipid metabolism and those related to suicidality. However, a genetic study by Lalovic et al. [20] failed to report significant differences in allele or genotype frequencies of proteins involved in cholesterol biosynthesis and transport between suicide cases and controls. A recent study found that the ABCG1 transporter may influence aggression-related traits [14]. At all events, most research has focused on cholesterol serum levels and the findings have been inconsistent. Differences in the criteria used to classify patients as "suicidal" (only attempters, or subjects with suicidal ideation), and differences in criteria used to define the comparison group make results difficult to compare. Some studies have confirmed the association between lower levels of cholesterol and suicidality $[2,4,9,15,19,21,23,25,27,30$, 35], while others find only a trend [32]. However, Tanskanen et al. [33] demonstrated the positive relationship of high serum total cholesterol concentration with increased risk of violent suicide. Deisenhammer et al. [8] found no significant differences in lipid levels between patients with and without suicide attempts, but noted a trend toward lower total cholesterol levels in patients who had used a violent method; Fiedorowicz and Coryell [12] reported no association between low cholesterol and subsequent suicide. Some of the studies compared suicidal psychiatric patients with the general population $[3,27$, 30], while others compared suicidal and non-suicidal patients with the same psychiatric diagnosis $[4,11,15$, $18,19,25,26]$. To date, we have found no studies in adult patients that assess this relationship in composite samples with different psychiatric diagnoses, or that consider lower levels of cholesterol in association with suicide attempts independently of specific psychiatric disorders.

Focusing on adolescent psychiatric patients, only two studies have included adolescent psychiatric samples. Favaro et al. [11] reported an association between lower cholesterol levels and suicidality in anorexic patients. However, these results should be regarded with caution because of influences of nutritional variables on cholesterol levels in these patients. Apter et al. [1] found higher serum cholesterol levels in a group of patients with suicidal behavior in an adolescent inpatient sample with different psychiatric diagnoses. In this study, the group of patients with suicidal behavior included: patients with suicidal ideation without suicide attempts, patients with suicidal tendencies and patients with suicide attempts. These authors also included eating disorder patients, who presented the highest serum cholesterol levels. In the suicidal behavior group, serum cholesterol correlated negatively with the degree of suicide behavior, suggesting perhaps that cholesterol levels could be inversely related with "acting", that is, with the step from suicide ideation to suicide attempt. Following on from this research, the present study focuses only on adolescent suicide attempters and excludes patients with suicidal ideation only, to study a specific suicidality outcome group. The objective is to provide further information about the potential role of serum cholesterol levels in suicide attempters in a general sample of psychiatric adolescent patients admitted to a hospital unit.

\section{Method}

\section{Subjects}

This case-control retrospective study was conducted in the inpatient unit of a Child and Adolescent Psychiatry and Psychology Department (Hospital Clinic of Barcelona). Over a 4-year period (2004-2007), 66 patients (49 females and 17 males) were consecutively admitted following attempted suicide. For being included in the attempted suicide group, patients must have committed an attempt to kill themselves (a suicide attempt with suicide ideation). Patients presenting self harm behavior without suicidal intention were not included in this group. The control group included 54 patients (39 females and 15 males) who were also admitted to the inpatient unit during the same period but who had no history of suicide attempts. Control subjects (non-suicide attempts) were paired with case subjects (suicide attempts) according to psychiatric diagnosis, age and gender. If no control subject with the same psychiatric diagnosis was enrolled during the same year of study, the corresponding case subject was left without a control pair. We failed to control 11 depressive cases, because we found only 35 patients with depressive symptoms without a history of suicide attempts in previous admissions. Exclusion criteria for both groups included taking medication known to alter lipid metabolism, dyslipemia, eating disorders and body mass index $<19$ or current eating binges, to avoid cholesterol and nutritional alterations due to these disorders. Exclusion criteria for control group included any suicide attempt in the past or recently. Patients with suicide ideation or tanatic ideation without lifetime history of suicide attempts were not excluded. All attempted suicide patients did not have control pairs because of the exclusion criteria. 


\section{Procedures}

Levels of cholesterol were obtained from the blood samples collected upon admission, after overnight fasting. All blood samples were measured by the same laboratory, using milligrams/deciliter $(\mathrm{mg} / \mathrm{dl})$. The normal range of total cholesterol at our hospital is defined as $148-247 \mathrm{mg} /$ dl. The American Heart Association endorsed with guidelines of the National Cholesterol Education Program's Expert Panel on Blood Cholesterol in children and adolescents (from 2 to 19 years) and determines as correct total cholesterol levels as less than $170 \mathrm{mg} / \mathrm{dl}$, borderline from 170 to $199 \mathrm{mg} / \mathrm{dl}$ and high from $200 \mathrm{mg} / \mathrm{dl}$ or greater. We did not find patients clearly outside the normal cholesterol range. Socio-demographic data, clinical diagnoses, psychotropic medication at admission in both groups and suicide methods used by the suicidal group were recorded. This study was approved by the Ethical Committee of Hospital Clinic of Barcelona. This study was retrospective and we did not have informed consent of the patients and their families. However, Ethical Committee approved the study because it did not imply any experimental procedure. The blood samples were obtained from the usual screening laboratory tests, carried out in all patients admitted at the hospitalization unit.

\section{Data analysis}

Results were analyzed using descriptive statistics. A Kolmogorov-Smirnov test was used to test for the normality of variables and then parametric tests were used, Student's $t$ test for quantitative variables and $\chi^{2}$ test for qualitative variables. Statistical analyses were performed using SPSS (14.0).

\section{Results}

Clinical characteristics and serum cholesterol levels in both groups of patients are listed and compared in the Table 1. There were no significant differences between the two groups with respect to gender, age or psychiatric diagnosis or in terms of antidepressant or antipsychotic medication at admission; nor were there significant differences between cholesterol levels in patients who were taking antipsychotic medication at admission and those who were not $(t=0.8$, $d f=23.3, p=0.37)$, nor with respect to gender $(t=1.7$, $d f=118, p=0.08)$. Levels of cholesterol were significantly lower in attempted suicide patients than in controls. When only patients with a diagnosis of depression were included, lower cholesterol levels were found in attempted suicide patients, though the difference was not statistically significant. If we focused on method of suicide attempts and divide the suicide sample in two big groups, overdosesuicide attempt (more frequent method) and non-overdose suicide attempts, the differences in cholesterol levels were not statistically significant (overdose-suicide attempt: mean $=144.51, \quad \mathrm{SD}=24.08 ; \quad$ non-overdose $\quad$ suicide attempts: mean $=152.42, \quad \mathrm{SD}=27.21 ; \quad t=1.16, \quad p=$ $0.249)$. We do not find patients clearly outside the normal cholesterol range.

\section{Discussion}

This is the first study to point out an association between suicide attempts and low levels of cholesterol in a psychiatric adolescent inpatient sample with a range of psychiatric disorders. Psychometric measures of suicidality were not used in the study; however, confirmed and substantiated reports of suicide attempts were used as dependent variables rather than potentially biased self-reports or unsubstantiated verbal reports of suicidal behaviors.

This finding is similar to those of most adult studies that have reported this association. Mean serum total cholesterol level obtained in our subjects with suicide attempts was similar with those reported by Kim et al. [19], and was near the lower end of the range defined as normal at our hospital. The study was not designed to identify a cutoff point for cholesterol.

Although suicide risk is known to increase in the presence of a history of personal or family psychiatric disorders, it has been shown that liability to suicidal behaviorspecifically, suicide attempts and completions-might be familial transmitted as a trait independent of psychiatric disorders [5]. As all subjects in our inpatient groups were in the acute period of their illness, our findings support the hypothesis that low levels of cholesterol might be associated with suicidal behavior. However, if lower blood cholesterol levels help to predict suicide, we may wonder whether this is the case in any psychiatric diagnosis. More studies are needed with larger samples, in which all psychiatric disorders are represented, to explore this issue further. The serotonin-suicide-cholesterol relationship might suggest that affective disorders involving serotonin system dysfunction would be the psychiatric illnesses with the highest rates of suicidality. However, studies with other psychiatric disorders have also found this association, raising the possibility that altered serotonin neurotransmission may also be linked with cholesterol and suicide with non-affective disorders. The findings are limited to psychiatric child and adolescent patients and may not be generalizable to other psychiatric patients.

Our study is limited due to the small sample size, which reduces the statistical power required to establish subgroups and to confirm the association between suicidal 
Table 1 Clinical characteristics and serum cholesterol levels in both groups

\begin{tabular}{|c|c|c|c|c|c|c|c|}
\hline & \multicolumn{2}{|c|}{ Suicide attempts group } & \multicolumn{3}{|c|}{ No suicide attempts group } & \multirow[t]{2}{*}{$\chi^{2}$} & \multirow[t]{2}{*}{$p$} \\
\hline & $N$ & $\%$ & $N$ & & $\%$ & & \\
\hline Gender: female & 49 & 74.2 & 39 & & 72.2 & 0.06 & 0.803 \\
\hline \multicolumn{8}{|l|}{ Psychotropic medication at admission } \\
\hline Antipsychotic & 9 & 13.6 & 11 & & 20.4 & 2.7 & 0.425 \\
\hline Antidepressant & 16 & 24.2 & 18 & & 33.3 & 2.1 & 0.545 \\
\hline \multicolumn{8}{|l|}{ Psychiatric diagnoses } \\
\hline Depression & 35 & 53 & 25 & & 46.3 & 1.6 & 0.978 \\
\hline Conduct disorder & 20 & 30.4 & 20 & & 37.1 & & \\
\hline Bipolar disorder & 4 & 6.1 & 3 & & 5.6 & & \\
\hline Schizophrenia & 2 & 3 & 2 & & 3.7 & & \\
\hline Obsessive-compulsive disorder & 2 & 3 & 2 & & 3.7 & & \\
\hline Personality disorders & 1 & 1.5 & 1 & & 1.8 & & \\
\hline Eating disorders & 1 & 1.5 & 1 & & 1.8 & & \\
\hline Mental retardation & 1 & 1.5 & 0 & & 0 & & \\
\hline \multicolumn{8}{|l|}{ Method } \\
\hline Drug overdose & 47 & 71.2 & & & & & \\
\hline Fall from a height & 9 & 13.7 & & & & & \\
\hline Wrist phlebotomy & 4 & 6.1 & & & & & \\
\hline Hanging & 2 & 3 & & & & & \\
\hline Caustic ingestion & 1 & 1.5 & & & & & \\
\hline Electrocution & 1 & 1.5 & & & & & \\
\hline Throwing oneself under a car & 1 & 1.5 & & & & & \\
\hline \multirow[t]{2}{*}{ Endovenous air injection } & 1 & 1.5 & & & & & \\
\hline & & Mean & SD & Mean & SD & $t$ & $p$ \\
\hline \multicolumn{2}{|l|}{ Age (years) } & 15.44 & 1.99 & 15.19 & 1.68 & 0.7 & 0.458 \\
\hline \multicolumn{2}{|c|}{ Cholesterol levels in total patients (mg/dL) } & 146.79 & 25.07 & 159.37 & 33.21 & -2.3 & 0.02 \\
\hline \multicolumn{2}{|c|}{ Cholesterol levels in depressed patients (mg/dL) } & 148.43 & 26.7 & 164.6. & 41.25 & -1.7 & 0.094 \\
\hline
\end{tabular}

behavior and lower cholesterol levels in all psychiatric diagnoses separately. Other limitations are the fact that we did not monitor body mass index; patients were not assessed with structured psychometric tests for suicidality, and inferring causal relations with retrospective studies is also problematic. If this association is replicated from future studies with bigger samples and methodological designs for studying cholesterol levels as a risk factor, this parameter could help to add more information to the clinicians to evaluated suicidal risk of our patients, in a similar way as we asked for psychopathology and familiar variables. Further studies assessing the relationship between cholesterol-related biological and genetic factors and suicide-related clinical factors are required to establish the role of cholesterol in this complex human behavior.

Acknowledgments All the authors of the article state that there is no actual or potential conflict of interest for this publication. The authors would like to thank Child and Adolescent Psychiatry and Psychology Department of Hospital Clínic of Barcelona for their collaboration.

\section{References}

1. Apter A, Laufer N, Bar-Sever M, Har-Even D, Ofek H, Weizman A (1999) Serum cholesterol, suicidal tendencies, impulsivity, aggression, and depression in adolescent psychiatric inpatients. Biol Psychiatry 46(4):532-541

2. Atmaca M, Kuloglu M, Tezcan E, Ustundag B, Gecici O, Firidin B (2002) Serum leptin and cholesterol values in suicide attempters. Neuropsychobiology 45(3):124-127

3. Atmaca M, Kuloglu M, Tezcan E, Gecici O, Ustundag B (2002) Serum cholesterol and leptin levels in patients with borderline personality disorder. Neuropsychobiology 45(4):167-171

4. Atmaca M, Kuloglu M, Tezcan E, Ustundag B (2003) Serum leptin and cholesterol levels in schizophrenic patients with and without suicide attempts. Acta Psychiatr Scand 108:208-214

5. Brent DA, Bridge J, Johnson BA, Connolly J (1996) Suicidal behaviour runs in families. A controlled family study of adolescent suicide victims. Arch Gen Psychiatry 53(12):1145-1152

6. Carlson GA, Rich CL, Grayson P, Fowler RC (1991) Secular trends in psychiatric diagnoses of suicide victims. J Affect Disord 21(2):127-132

7. Cremniter D, Jamain S, Kollenbach K, Alvarez JC, Lecrubier Y, Gilton A et al (1999) CSF 5-HIAA levels are lower in impulsive 
as compared to non-impulsive violent suicide attempters and control subjects. Biol Psychiatry 45(12):1572-1579

8. Deisenhammer E, Karin K-R, Liensberger D, Kemmler G, Hinterhuber H, Fleischhacker W (2004) No evidence for an association between serum cholesterol and the course of depression and suicidability. Psychiatry Res 121:253-261

9. Diaz-Sastre C, Baca-Garcia E, Perez-Rodriguez M, García-Resa E, Ceverino A, Saiz-Ruiz J et al (2007) Low plasma cholesterol levels in suicidal males: a gender and body mass index-matched case-control study of suicide attempters and non-attempters. Prog Neuropsychopharmacol Biol Psychiatry 31:901-905

10. Engelberg H (1992) Low serum cholesterol and suicide. Lancet 339(8795):727-729

11. Favaro A, Caregaro L, Di Pascoli L, Brambilla F, Santonastaso P (2004) Total serum cholesterol and suicidality in anorexia nervosa. Psychosom Med 66(4):548-552

12. Fiedorowicz Jess G, Coryell W (2007) Cholesterol and suicide attempts: a prospective study of depressed inpatients. Psychiatry Res 152:11-20

13. Franke L, Uebelhack R, Muller-Oerlinghausen B (2002) Low CSF 5-HIAA level in high-lethality suicide attempters: fact or artifact? Biol Psychiatry 52(4):375-376 author reply 376-377

14. Gietl A, Giegling I, Hartmann AM, Schneider B, Schnabel A, Maurer K et al (2007) ABCG1 gene variants in suicidal behavior and aggression-related traits. Eur Neuropsychopharmacol 17:410-416

15. Guillem E, Pélissolo A, Notides C, Lépine JP (2002) Relationship between attempted suicide, serum cholesterol level, and novelty seeking in psychiatric in-patients. Psychiatry Res 112:83-88

16. Jokinen J, Nordström AL, Nordström P (2007) The relationship between CSF HVA/5-HIAA ratio and suicide intent in suicide attempters. Arch Suicide Res 11(2):187-192

17. Jones JS, Stanley B, Mann JJ, Frances AJ, Guido JR, TraskmanBendz L et al (1990) CSF 5-HIAA and HVA concentrations in elderly depressed patients who attempted suicide. Am J Psychiatry $147(9): 1225-1227$

18. Kim YK, Myint AM (2004) Clinical application of low serum cholesterol as a indicator for suicide risk in major depression. $\mathrm{J}$ Affect Disord 81:161-166

19. Kim YK, Lee HJ, Kim JY, Yoon DK, Choi SH, Lee MS (2002) Low serum cholesterol is correlated to suicidality in a Korean sample. Acta Psychiatr Scand 105(2):141-148

20. Lalovic A, Sequeira A, DeGuzman R, Chawky N, Lesage A, Seguin M, Turecki G (2004) Investigation of completed suicide and genes involved in cholesterol metabolism. J Affect Disord 79:25-32

21. Lalovic A, Merkens L, Russell L, Arsenault-Lapierre G, Nowaczyk MJ, Porter FD et al (2004) Cholesterol metabolism and suicidality in Smith-Lemli-Opitz syndrome carriers. Am J Psychiatry 161(11):2123-2126
22. Lalovic A, Levy E, Luheshi G, Canetti L, Grenier E, Sequeira A, Turecki G (2007) Cholesterol content in brains of suicide completers. Int J Neuropsychopharmacol 10(2):159-166

23. Lester D (2002) Serum cholesterol levels and suicide: a metaanalysis. Suicide Life Threat Behav 32:333-346

24. Marazziti D, Presta S, Silvestri S, Battistini A, Mosti L, Balestri C et al (1995) Platelet markers in suicide attempters. Prog Neuropsychopharmacol Biol Psychiatry 19(3):375-383

25. Marcinko D, Martinac M, Karlovic D, Filipcic I, Loncar C, Pivac N, Jakovljevic M (2005) Are there differences in serum cholesterol and cortisol concentrations between violent and non-violent schizophrenic male suicide attempters? Coll Antropol 29(1): 153-157

26. Marcinko D, Pivac N, Martinac M, Jakocljevic M, MihaljevicPeles A, Muck-Seler D (2007) Platelet serotonin and serum cholesterol concentrations in suicidal and non-suicidal male patients with a first episode of psychosis. Psychiatry Res 150:105-108

27. Morgan RE, Palinkas LA, Barret-Connor RE, Wingard DL (1993) Plasma cholesterol and depressive symptoms in older men. Lancet 341(8837):75-79

28. Nordstrom P, Samuelsson M, Asberg M, Traskman-Bendz L, Aberg-Wistedt A, Nordin C, Bertilsson L (1994) CSF 5-HIAA predicts suicide risk after attempted suicide. Suicide Life Threat Behav 24(1):1-9

29. Pandey GN, Pandey SC, Janicak PG, Marks RC, Davis JM (1990) Platelet serotonin-2 receptor binding sites in depression and suicide. Biol Psychiatry 28(3):215-222

30. Partonen T, Haukka J, Virtamo J, Taylor PR, Lonnqvist J (1999) Association of low serum cholesterol with major depression. $\mathrm{Br}$ J Psychol 175:259-262

31. Roy A, Agren H, Pickar D, Linnoila M, Doran AR, Cutler NR et al (1986) Reduced CSF concentrations of homovanillic acid and homovanillic acid to 5-hydroxyindolacetic acid ratios in depressed patients: relationship to suicidal behavior and dexametasone suppression. Am J Psychiatry 143(12):1539-1545

32. Sullivan PF, Joyce PR, Bulik CM, Mulder RT, Oakley-Browne M (1994) Total cholesterol and suicidality in depression. Biol Psychiatry $36(7): 472-477$

33. Tanskanen A, Vartrianinen E, Tuo-Milehto J, Viinamaeki IL, Leitonen J, Puska P (2000) High serum cholesterol and risk of suicide. Am J Psychiatry 157:648-650

34. Vevera J, Zdenek F, Kvasnicka T, Zdenek H, Stárkova L, Ceska $\mathrm{R}$ et al (2005) Cholesterol-lowering therapy evokes time-limited changes in serotonergic transmission. Psychiatry Res 133: 197-203

35. Zureik M, Courbon D, Ducimetiere P (1996) Serum cholesterol concentration and death from suicide in men. $\mathrm{Br}$ Med $\mathrm{J}$ 313: 649-652 